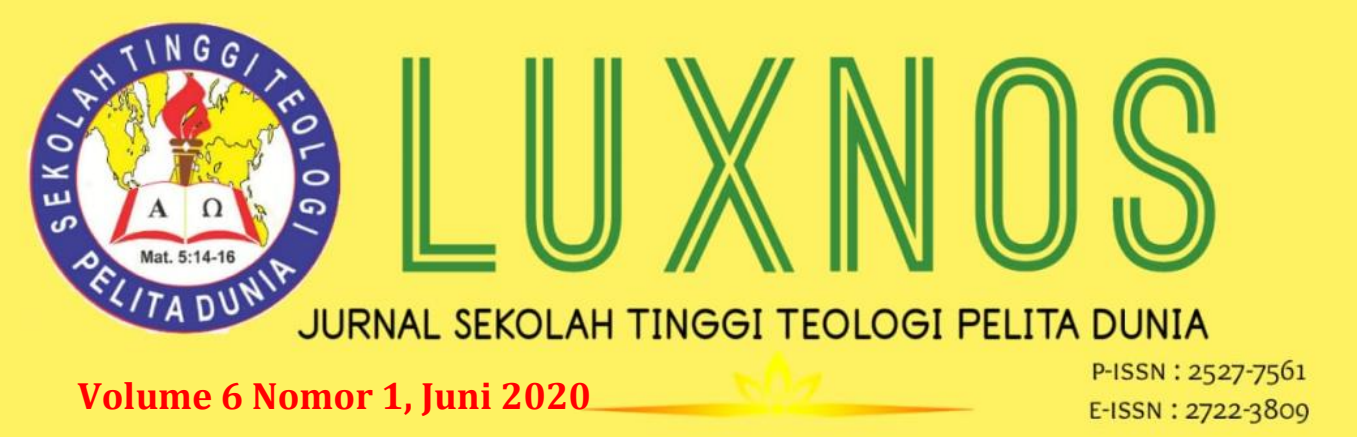

\title{
Kajian Teologis tentang Persepuluhan
}

\author{
Ndaru Sarjono \\ Sekolah Tinggi Teologi Pelita Dunia,sarjonondaru@gmail.com
}

\begin{abstract}
The scientific work discusses tithing which is often heard by believers, but more often is not understood. This topic is believer's struggle because of his ignorance of the reasons for give the tithing. This scientific work the author will put forward several theological concepts regarding tithing from The Old Testament until The New Testament. Presumably research from this scientific work can help believers to understand the theological concepts of tithing.
\end{abstract}

Keywords : Bible, believers, tithe.

\begin{abstract}
Abstrak : Karya ilmiah ini membahas tentang persepuluhan yang sering didengar oleh orang percaya, akan tetapi lebih sering tidak dimengerti orang percaya. Topik ini merupakan pergumulan bagi setiap orang percaya karena ketidaktahuannya apa yang menjadi alasan untuk memberikan persepuluhan. Dalam karya ilmiah ini penulis akan mengemukakan beberapa konsep teologis mengenai persepuluhan dari Perjanjian Lama sampai Perjanjian Baru. Kiranya penelitian dalam karya ilmiah ini dapat membantu setiap orang percaya untuk memahami konsep teologis dari persepuluhan.
\end{abstract}

Kata Kunci : Alkitab, orang percaya, persepuluhan.

\section{Pendahuluan}

Mengelola keuangan dengan baik sebagai salah satu bentuk berkat Tuhan, merupakan hal penting yang seharusnya ada di dalam kehidupan orang percaya. John R. Muther mengatakan bahwa perlu disadari oleh setiap orang percaya bahwa seluruh kehidupannya berada di bawah pemeliharaan Tuhan, termasuk di dalamnya perihal keuangan, sehingga kehidupan kekristenan seharusnya berimplikasi pada perilaku orang-orang percaya terhadap kekayaan dan kemiskinan.1 Oleh sebab itu, setiap orang percaya seharusnya dapat dengan bijak mengelola keuangan yang telah dipercayakan oleh Tuhan. Tuhan Yesus juga mengajarkan bahwa salah satu tanda spiritualitas yang sejati adalah sikap yang benar terhadap harta dan kekayaan (Mat. 6:19-20). Menurut Stephen Olford, "Salah satu fondasi iman Kristen adalah bahwa orang percaya tidak dapat memberikan sesuatupun kepada Tuhan, tanpa Tuhan yang

1 John R. Muther, Money and the Bible, (Grand Rapid: Baker, 1987), 6. 
Volume 6 Nomor 1, Juni 2020

terlebih dahulu memberikannya."2 Jadi, tidak ada alasan bagi orang percaya untuk tidak memberikan persembahan kepada Tuhan, karena semua adalah pemberian dari pada Tuhan. Memberi merupakan aspek penting dalam pelayanan dan dalam kehidupan orang percaya.

Persepuluhan merupakan salah satu aspek penting dalam hal memberi yang tidak dapat diabaikan dalam kehidupan orang percaya. Banyak orang percaya mengalami kebingungan mengenai persepuluhan. Orang pecaya yang satu seringkali mendengar dari banyak orang percaya yang lain bahwa persepuluhan adalah sebuah kewajiban yang harus ditaati oleh semua orang percaya, karena setiap orang percaya telah diberkati atau supaya orang percaya diberkati.3 Orang percaya yang mewajibkan persepuluhan sebagai keharusan seringkali memakai Maleakhi 3:10 sebagai dasar alkitabnya, "Bawalah seluruh persembahan persepuluhan itu ke dalam rumah perbendaharaan, supaya ada persediaan makanan di rumah-Ku dan ujilah Aku, firman TUHAN semesta alam, apakah Aku tidak akan membukakan bagimu tingkap-tingkap langit dan mencurahkan berkat kepadamu sampai berkelimpahan." Penting bagi setiap orang percaya untuk mengetahui bahwa pendekatan alkitabiah sangat berbeda dengan pendekatan ayatiah. Pendekatan alkitabiah lebih memperhatikan pesan utama keseluruhan Alkitab tentang sebuah tema terkhusus di sini adalah tentang persepuluhan. Sedangkan pendekatan ayatiah biasanya hanya sekadar mengambil ayat-ayat favorit dan manarik darinya sebagai kesimpulan. Oleh karena itu, sungguh adalah perlu diperhatikan, bagaimana Alkitab secara keseluruhan berbicara mengenai persepuluhan.

\section{Metode Penelitian}

Untuk membahas dan menyajikan suatu pokok permasalahan yang dikemukakan, maka metode penelitian yang digunakan adalah metode kualitatif deskriptif.4 Metode deskriptif merupakan suatu metode dalam meneliti status kelompok manusia, suatu objek, suatu set kondisi, suatu sistem pemikiran ataupun suatu kelas peristiwa pada masa sekarang.5 Adapun jenis pengumpulan data yang digunakan adalah library research. Literatur yang digunakan dalam penelitian ini yaitu kajian pustaka. Jadi untuk menjelaskan pokok permasalahan mengenai persepuluhan, penulis menggunakan metode kualitatif deskriptif dan mengumpulkan data dari pustaka.

2 Stephen Olford, The Grace of Giving, (Grand Rapids: Baker, 1972), 10.

${ }^{3}$ Douglas W. Johnson, The Tithe: Challenge or Legalism, (Nashville: Abingdon, 1984), 17.

4 Sugiyono, Cara Mudah Menyusun: Skripsi, Tesis dan Disertasi, (Bandung: Alfabeta, 2013), 30.

${ }^{5}$ Nazir, Metode Penelitian (Jakarta: Ghalia Indonesia, 2011), 186. 
Volume 6 Nomor 1, Juni 2020

\section{Hasil dan Pembahasan}

Sebelum lebih lanjut menyelidiki bagaimana sesungguhnya konsep alkitabiah mengenai persepuluhan, terlebih dahulu penulis menyajikan difinisi dari persepuluhan. Kata persepuluhan adalah kata yang berasal dari kata dalam bahasa Ibrani yaitu maaser atau maasar yang diterjemahkan dalam bahasa Inggris menjadi tithe atau tenth part. Kemudian kata tithe ini dipakai secara luas untuk mendefinisikan persepuluhan, yang oleh Easton's Biblical Dictionary didefinisikan sebagai sepersepuluh dari hasil bumi yang dikuduskan dan dikhususkan untuk tujuan khusus.6 Kamus tersebut lebih menekankan aspek rohani dalam mendefinisikan persepuluhan. Sedangkan kamus lain, yaitu kamus Haag mendefinisikan persepuluhan dengan menekankan pada fungsinya dalam Alkitab Perjanjian Lama, yaitu sebagai pajak untuk Raja (1 Sam. 8:15-17) dan pada Bait Suci sebagai nafkah penghidupan para imam dan kaum Lewi (Kej. 14:20; 28:22),7 Dari kedua definisi yang hampir sama tersebut, dapat disimpulkan bahwa persepuluhan adalah memberi sepersepuluh dari harta yang dimiliki kepada Tuhan sebagai ucapan syukur atas segala berkat-Nya yang kemudian digunakan untuk membantu pelayanan dalam hal ini untuk nafkah penghidupan para imam dan orang-orang Lewi sebagai pelayan di Bait Suci.

\section{a. Asal Mula Persepuluhan}

Zaman sebelum munculnya hokum Taurat catatan mengenai persepuluhan hanya muncul ketika Abraham memberikan sepersepuluh hasil rampasan perangnya kepada Melkisedek (Kej. 14:20, 22) dan ketika Yakub bernazar kepada Tuhan (Kej. 28:22). Di sini sangat jelas bahwa tidak ada peraturan legal sama sekali. Namun dapat diduga bahwa jumlah sepersepuluh yang diberikan oleh Abraham kepada Melkisedek dan oleh Yakub kepada kepada Tuhan memang menjadi tradisi budaya di wilayah Timur Dekat Kuno. Selain itu, dalam peristiwa Yakub, Yakub memberikan persepuluhan kepada Tuhan sebagai ungkapan syukur dalam konteks perjanjian dengan Allah dan bukan sebagai sebuah kewajiban.8

Dari cerita mengenai Abraham dan Yakub tersebut didapati bahwa sesungguhnya dasar pelaksanaan persepuluhan bukanlah semata-mata karena keberadaan imam Lewi, melainkan karena keberadaan Tuhan. Abraham dan Yakub melakukannya sebagai suatu tindakan penyembahan sebab pembayaran Disc).

6 Brandon Staggs, Power Bible CD 3.7a, (Bronson: Online Publishing, 2002), n. p. (Compact

7 YLSA, SABDA/OLB versi 7.03 (TK: TP, 1997-1999), n. p. (Sabda.org online)

8 Yamowa'a Bate'e, Mengungkap Misteri Persepuluhan, (Bandung: Yayasan Andi, 2008), 34. 
persepuluhan adalah saksi yang signifikan dalam hubungannya dengan Tuhan.9 Dengan demikian, dapatlah disimpulkan bahwa pada mulanya persepuluhan bukanlah sebuah kewajiban yang harus dilakukan melainkan sebuah ucapan syukur kepada Tuhan.

\section{b. Zaman Hukum Taurat}

Persepuluhan kemudian menjadi sesuatu yang legal di zaman hukum Taurat Musa. Hal pertama yang harus ditekankan sehubungan dengan banyaknya hukum dan peraturan dalam kitab Taurat adalah bahwa semua hukum semata-mata mencerminkan tuntutan agar umat Israel percaya, tunduk dan patuh kepada Tuhan. Persepuluhan dalam hal ini hanyalah menjadi sebuah contoh penerapannya agar umat Israel tunduk dan taat kepada Tuhan. Pesan utamanya adalah keseluruhan hidup yang diabdikan kepada Tuhan.

Dalam Imamat 27:30-34 mencatat Tuhan menetapkan persepuluhan menjadi suatu persembahan yang wajib diberikan oleh bangsa Israel sebagai umat pilihanNya. Dalam hal ini persepuluhan menjadi suatu lambang ketaatan bangsa Israel kepada ketentuan Tuhan. Pada zaman hukum Taurat persepuluhan bukan lagi sekadar persembahan yang diberikan dengan sukarela atas inisiatif diri sendiri, melainkan menjadi suatu keharusan yang pelaksanaannya diatur sepenuhnya oleh Tuhan. Persepuluhan menjadi semacam pajak wajib bagi bangsa Israel, yang diperkenalkan oleh Tuhan melalui Musa dengan didasari dalam bangsa Israel ada yang disebut dengan sistem keimaman dan sistem korban.10 Tujuan dari persepuluhan ini tidak lain adalah mengajar umat Israel untuk selalu mengutamakan Tuhan dalam hidupnya (Ul. 14:23).

Dalam Bilangan 18 secara khusus menjelaskan bahwa persembahan persepuluhan harus diberikan kepada suku Lewi sebagai ganti tidak diperolehnya tanah pusaka bagi suku Lewi. Namun tidak berhenti sampai disitu, suku Lewi juga harus mempersembahkan sepersepuluh dari pengshasilan yang diterimanya dan memberikannya kepada imam Harun.11 Hal ini menunjukkan bahwa persembahan persepuluhan menjadi kewajiban bagi seluruh umat Israel tanpa terkecuali.

Dalam Ulangan 12 persembahan persepuluhan diatur sedemikian sehingga sama sekali berbeda dengan peraturan yang sebelumnya. Persembahan persepuluhan harus diberikan bersama dengan persembahan-persembahan

9 http://www.cogeternal.org/text/035tithingtoday.htm, 21 April 2011.

10 Ibid.

11 Herbert Wolf, Pengenalan Pentateukh, (Malang: Gandum Mas, 2004), 236. 
Volume 6 Nomor 1, Juni 2020

lainnya ke tempat yang dipilih Tuhan. Setelah sampai di tempat yang dipilih Tuhan, umat Israel diharuskan untuk memakan persembahan persepuluhannya sendiri bersama dengan seisi keluarga dan orang Lewi dengan sukacita. Dengan demikian dapat disimpulkan bahwa dalam Ulangan 12 ini persembahan persepuluhan diberikan kepada Tuhan untuk dinikmati bersama dengan komunitas dalam perjamuan kasih.

\section{c. Kitab-Kitab Lain dalam Perjanjian Lama}

Peraturan persembahan persepuluhan juga muncul dalam kitab-kitab lain di luar kitab Taurat Musa. Dalam 2 Tawarikh 31:5-6 dan Nehemia 10:37-38; 12:44; $13: 5,12$. Persembahan persepuluhan dalam bagian ini mengikuti tradisi dari Bilangan 18 yaitu diberikan kepada suku Lewi oleh karena suku Lewi tidak memperoleh bagian dari pembagian tanah Israel.12 Dalam kitab nabi-nabi tidak banyak dijumpai catatan mengenai persembahan persepuluhan kecuali dalam kitab Maleakhi. Hal ini menunjukkan bahwa persembahan persepuluhan lebih dekat dengan tradisi imamat atau ritual dan bukan dengan tradisi sosial atau kenabian.

Dalam Amos 4:4 persembahan persepuluhan dibahas dengan nada yang kritis dan negatif. Dapat diketahui bahwa yang terjadi pada saat itu adalah peraturan hukum dilaksanakan secara legalitas namun kehilangan semangat sosialnya, sehingga dengan keras nabi Amos menyampaikan pesan Tuhan. Jadi di sini nabi Amos mengajukan kritik atas persembahan persepuluhan yang diberikan bangsa Israel, karena persembahan persepuluhan itu diberikan terlepas dari makna sosialnya. Makna sosial hilang ketika yang dilakukan adalah perbuatan jahat (Am. 4:4) dan memeras orang lemah, menginjak orang miskin (Am. 4:1). Makna sosial hilang ketika bangsa Israel memberikan persembahan persepuluhan bukan dalam rangka ketaatan kepada Allah namun justru untuk menyombongkan diri dan mendapat pujian (Am. 4:5). Jadi persembahan persepuluhan yang tadinya dimaksudkan untuk pelayanan sosial berubah menjadi suatu aturan kaku yang dimanipulasi untuk menutupi penindasan sosial.

Dalam Maleakhi 3:10 sebelumnya harus diketahui bahwa bahasa religius yang dipakai dalam kitab Maleakhi sangat legalisasi dengan keinginan untuk menegakkan aturan agamawi. Namun hal ini bukanlah yang utama sebab pesan utama dalam kitab Maleakhi adalah mengenai kesetiaan Allah yang direspons tidak sepantasnya oleh umat Israel. Sejak awal kitab Maleakhi ditegaskan bahwa Tuhan mengasihi bangsa Israel (Mal.1:2-5). Namun sekalipun bangsa Israel sudah

12 Lukas Vischer, Tithing in the Early Church, (Philadelphia: Fortress, 1966), 5. 
dikasihi Tuhan, bangsa Israel tetap saja melakukan tindakan yang menyedihkan dan penuh cemar dengan memberi persembahan yang tidak layak kepada Tuhan (Mal. 1:6-14), bahkan para imamnya terlibat dalam perusakan moral umat Israel (Mal. 2:1-9), selanjutnya umat Israel yang dituntut untuk memelihara kemurnian iman justru kawin dengan bangsa lain (Mal. 2:10-16). Terlihat dengan jelas bahwa hubungan kasih Tuhan dan manusia tidak seimbang, bagaimana Tuhan mengasihi manusia namun manusia membalas-Nya dengan kejahatan. Semua kejahatan yang dilakukan umat Israel menunjukkan ketidakpercayaan umat Israel bahwa Tuhan yang selalu memeliharanya dengan setia. Itulah sebabnya Tuhan menegaskan bahwa Tuhan tidak pernah berubah dan Ia akan tetap setia (Mal3:6).

Respons dalam bentuk kejahatan yang dilakukan oleh umat Israel terhadap kasih Tuhan ini tentu sangat menyedihkan hati-Nya. Tuhan hanya menuntut umat Israel untuk hidup taat yang diwujudkan dalam pemberlakuan hukum dan peraturan, tetapi umat Israel malah melanggarnya termasuk dalam hal persepuluhan. Itulah sebabnya Tuhan seperti menantang umat Israel untuk membuktikan kasih setia Tuhan kembali dan setelah itu barulah muncul ayat 10 . Dengan demikian ayat 10 ini bukan bernuansa pengaturan mengenai persembahan persepuluhan, namun sebuah tantangan dari Tuhan untuk membuktikan kesetiaan Allah. Jadi, Maleakhi 3:10 harus dipahami dalam kerangka, umat Israel memberi karena telah menerima dari Tuhan dan bukan sebaliknya, umat Israel memberi supaya menerima.

\section{d. Zaman Perjanjian Baru}

Jika dalam Perjanjian Lama persepuluhan ditekankan dengan jelas dan diatur sedemikian rupa sebagai bagian dari hukum yang harus ditaati, maka dalam Perjanjian Baru persepuluhan tidak terlalu banyak dibahas. Dalam Injil, persepuluhan disebutkan dalam suasana yang sangat kritis dan profetik. Yesus mengecam orang-orang Farisi yang terlalu mematuhi aturan persepuluhan namun kehilangan semangat keadilan sosial dan belas kasihan di baliknya. Dapat disimpulkan bahwa Yesus justru ingin menunjukkan betapa tidak berartinya persepuluhan diberikan dibandingkan dengan solidaritas sosial di baliknya. Jadi, Yesus memang tidak menolak persepuluhan, namun Dia juga tidak menganjurkannya tetapi yang Yesus lakukan adalah mengajarkan bahwa pelayanan orang percaya bukan didasarkan pada praktik persepuluhan, namun pada belas kasihan.13

13 Ibid. 5. 
Sama seperti tradisi kenabian dalan kitab Amos yang mengkritik kehidupan umat Israel yang menekankan kesalehan ritual dan mengabaikan kesalehan sosial, Yesus pun menyikapi dengan hal yang sama kritisnya ketika memaparkan kisah seorang Farisi (Luk.18:12) yang dengan bangganya mematuhi aturan persepuluhan, namun memiliki sikap yang sombong dan merendahkan orang lain dan bagi Yesus orang semacam ini akan direndahkan (Luk. 18:14).

Dalam surat Ibrani rupanya juga terdapat catatan mengenai persepuluhan, yaitu ketika dibicarakan kembali kisah pemberian persepuluhan oleh Abraham kepada Melkisedek dan itu pun persepuluhan muncul bukan sebagai tema utama, karena yang dibicarakan sebenarnya adalah mengenai perbandingan Imam Besar Melkisedek dengan Yesus sebagai Imam Besar Perjanjian Baru. Jadi fokus dari Ibrani 7:1-10 bukan pada persembahan persepuluhan melainkan berfokus pada Yesus (Kristosentris).

Sikap Yesus yang tidak menyarankan persepuluhan secara tersurat konsisten dengan surat-surat Paulus yang sama sekali tidak berbicara mengenai persepuluhan. Paulus berkali-kali berbicara mengenai uang dan tidak ada satu kali pun berbicara mengenai persepuluhan. Sehingga kesimpulannya adalah persepuluhan tidak disebutkan lagi sebagai aturan khusus dalam Perjanjian Baru, namun konsep persepuluhan dikembangkan menjadi lebih luas lagi, yaitu memberi. Sebab keuangan merupakan salah satu aspek penting dalam pelayanan yang tidak dapat diabaikan.

\section{Kesimpulan}

Setelah meneliti seluk-beluk mengenai persembahan persepuluhan, mulai dari zaman Perjanjian Lama sampai pada zaman Perjanjian Baru maka dapat diambil beberapa kesimpulan adalah sebagai berikut:

1. Persepuluhan sudah dimulai dari Abraham yang kemudian menjadi bagian ketetapan Tuhan yang dilegalkan dalam hukum Taurat.

2. Persepuluhan diberikan kepada orang-orang Lewi dan kepada imam-imam zaman Perjanjian Baru dilakukan oleh karena orang-orang dari suku Lewi adalah sekelompok umat Tuhan yang mengabdikan sepenuh hidupnya bagi Allah dan tidak memperoleh bagian atas tanah perjanjian.

3. Persepuluhan bukanlah pemberian untuk mendapatkan berkat Tuhan, malainkan oleh karena Tuhan telah terlebih dahulu memberkati, maka orang percaya meresponsnya dengan memberi persepuluhan. 


\section{JURNAL LUXNOS}

Volume 6 Nomor 1, Juni 2020

4. Pernyataan bahwa sepersepuluh penghasilan orang percaya adalah hak atau milik Tuhan adalah benar, namun perlu disadari bahwa seluruhnya yang dimiliki orang percaya adalah milik Tuhan.

5. Sekalipun praktik pemberian persepuluhan sebagai kewajiban adalah salah, namun bukan berarti orang percaya dilarang melakukannya. Pemberian persepuluhan boleh dilakukan namun dengan motivasi yang tulus, sukarela dan disertai dengan pemahaman yang benar yaitu bahwa persepuluhan adalah sebagai wujud komitmen pribadi dengan Tuhan.

\section{Referensi}

Bate'e, Yamowa'a, Mengungkap Misteri Persepuluhan, Bandung: Yayasan Andi, 2012. http://www.cogeternal.org/text/035tithingtoday.htm, 21 April 2011.

Johnson, Douglas W. The Tithe: Challenge or Legalism, Nashville: Abingdon, 1984.

Muther, John R. Money and the Bible, Grand Rapid: Baker, 1987.

Olford, Stephen. The Grace of Giving, Grand Rapids: Baker, 1972.

Staggs, Brandoon. Power Bible CD 3.7a, Bronson: Online Publishing, 2002.

Sugiyono, Cara Mudah Menyusun: Skripsi, Tesis dan Disertasi, Bandung: Alfabeta, 2013.

Vischer, Lukas. Tithing in the Early Church, Philadelphia: Fortress, 1966.

Wolf, Herbert. Pengenalan Pentateukh, Malang: Gandum Mas, 2004.

YLSA, SABDA/OLB versi 7.03 (TK: TP, 1997-1999). 